\title{
Six Myths of Human Resource Management
}

\author{
Cam Caldwell $^{1} \&$ Verl Anderson ${ }^{1}$ \\ ${ }^{1}$ American University in the Emirates, USA \\ Correspondence: Verl Anderson, Dixie State University, USA
}

Received: March 3, 2021

Accepted: May 31, $2021 \quad$ Online Published: June 18, 2021

doi:10.5430/bmr.v10n2p1

URL: https://doi.org/10.5430/bmr.v10n2p1

\begin{abstract}
Introduction: For decades the Human Resource Management (HRM) strategic role has been viewed as limited in its effectiveness. Human Resource Professionals (HRPs) have been criticized for their lack of formal preparation - when that preparation even exists. According to Gomez-Mejia (2015) and colleagues, fewer than one-third of all HRPs have any academic preparation in HRM and most lack an understanding of the legal, professional, and technical principles of their profession.

Objective: The purpose of this paper is to focus on six myths about HRM and the role of HRPs that are frequently held by Top Management Team (TMT) members, business practitioners, and even many HRPs. The failure of so many HRPs and TMTs to recognize the fallacies in these myths is a cause of organizational dysfunction and undermines the ability of HRPs to be ethical stewards who serve and protect the best interests of their organizations.
\end{abstract}

Methods: The paper begins by briefly identifying seven key strategic functions of HRM in distinguishing the HRPs' staff role in successful organizations.

Results: We describe the context of today's challenging work environment in which HRPs perform their labors and identify six myths that plague the HRM profession and undermine the effectiveness of many modern organizations.

Conclusions: We conclude the paper with a challenge to TMT members and HRPs to raise the bar and increase the accountability of those who deliver HRM services within their organizations.

Keywords: HRM, Human Resource Management, Strategic functions of Human Resource Management, HRM challenges, TMTs, HRPs

\section{Introduction}

For decades the Human Resource Management (HRM) strategic role has been viewed as limited in its effectiveness (Barney \& Wright, 1998). Human Resource Professionals (HRPs) have been criticized for their lack of formal preparation - when that preparation even exists (Gomez-Mejia Balkin \& Cardy, 2015). According to Gomez-Mejia and colleagues (2015), fewer than one-third of all HRPs have any academic preparation in HRM and most lack an understanding of the legal, professional, and technical principles of their profession. The quality of HRM decisions and the often-conflicting policies and programs that organizations initiate have been identified as the source of much organization dysfunction by Stanford University's Jeffrey Pfeffer (1998) in his widely-acclaimed book, The Human

\section{Equation.}

The purpose of this paper is to focus on six often-misunderstood myths about HRM and the role of HRPs that are frequently held by Top Management Team (TMT) members, business practitioners, and many HRPs. The failure of HRPs and TMTs to recognize the fallacies in these myths undermines the ability of HRPs to be ethical stewards who serve and protect the best interests of their organizations (Caldwell \& Anderson, 2018).

The paper begins by briefly identifying seven key strategic functions of HRM and distinguishing the HRPs' staff role in contributing to successful organization results. Following that introduction, we describe the context of today's challenging work environment in which HRPs perform their labors. We identify six myths that plague the HRM profession, explain why those myths are commonly held, and clarify more productive roles for HRPs in contrast with these myths. We conclude the paper with a challenge to TMT members and HRPs to raise the bar and increase the accountability of those who deliver HRM services within their organizations. 


\section{Seven Strategic Functions of HRM}

HRPs add value by linking people, values, and performance with an organization's overall strategy and creating aligned human resource systems (Caldwell, Truong, Linh \& Tuan, 2011; Ulrich, Younger, Brockbank \& Ulrich, 2012). Strategically, the HRM responsibility is to support the TMT and perform seven strategic roles in that process (Caldwell \& Anderson, 2018).

- Create and Sustain an Organization Culture - That culture aligns strategic goals with values, assumptions, programs, policies, and activities that convey how an organization performs. The TMT is responsible for establishing that culture but HRPs play a major role in conducting the day-to-day activities that affirm and align the culture's character (Schein \& Schein, 2016).

- Demonstrate Technical Excellence - HRPs are responsible for acquiring and demonstrating "profound knowledge" (Deming, 2000) that include a multitude of legal, technical, and behavioral competencies that are essential to their profession and that add value to their organizations.

- Function as Business Partners - HRPs function as business partners to the respective departments of their organization under the direction of the TMT. In the role of business partner, they are internal consultants and subject matter experts for department heads and supervisors as they accomplish organizational goals (Price, 2007).

- Advocate for and Empower Employees - Wise HRPs recognize that their ability to communicate employee needs enhances their value to the TMT. As advocates for employees and their personal and professional growth, HRPs understand that a transformational leadership approach to employee relations enables them to engage and empower employees (Clifton \& Harter, 2019).

- Provide Research about Best Practices - HRPs have the professional responsibility to constantly research best practices associated with organization development and HRM (Kreitner \& Kinicki, 2006). HRPs recognize that being "as good as" their competitors provides no competitive advantage and that effective HRPs play a key role in sharing their research about improving the organization with the TMT (Collins \& Clark, 2003).

- Support Constant Learning and Improvement - HRPs are involved in assessing organization training and development needs and helping their organizations to meet those needs. Constant learning and continuous improvement are hallmarks of every successful organization. HRPs utilize their knowledge and skills to also conduct training classes and to coach individuals (Perez-Lopez, Peon \& Ordas, 2005).

- Monitor the Climate and Support Change - In supporting the TMT's need for organizational change, HRPs monitor employee attitudes and provide important information crucial to making successful organization transitions (Kotter, 2012). As key players in the building of programs that enhance employee relations, the HRM staff help to prevent or to smooth out problems that arise in the change management process (Beer, 2009).

Each of these seven strategic roles assists the TMT in implementing systems, policies, and practices that align with an organization's strategic purpose. The scope and depth of these seven areas of responsibility provide a framework for understanding the significant contributions that highly competent HRPs can make as they assist the organization.

\section{The Context of HRM Challenges}

TMT members view HRPs as valuable in utilizing human capital and in helping the organization to accomplish results efficiently and effectively. However, most TMT members lack familiarity with the nuances associated with world-class HRM systems or the complex skills, knowledge, and insights required for HRPs to perform the seven strategic HRM roles at an optimal level (Caldwell \& Anderson, 2018). The modern business organization struggles to compete in today's global marketplace.

The competitive advantage of modern companies has become increasingly dependent upon an inherently contradictory set of employee skills (Christensen, 2016). Since 2005 90\% of the new jobs created in the US are part-time or temporary - with Harvard's Lawrence Katz and Princeton University's Alan Krueger (2019) reporting that " $94 \%$ of net job growth in the past decade was in the alternative work category". The plain truth is that companies have hired temporary, or "gig" employees, to avoid paying costly retirement and health care insurance benefits. This policy has of hiring part-time and temporary employees has resulted in a decline in employee loyalty, engagement, and long-term commitment (Beer, 2009).

Many of today's businesses have discovered that their most successful competitors have initiated "disruptive innovations" which introduce new standards and compete at a lower price - eroding company's profit margins (Christensen \& Raynor, 2013). These companies have discovered that they need employees that are innovative, creative, and willing to take well-planned risks in developing new products and markets (Collins \& Hansen, 2011; 
Hansen, 2019). The employee qualities of innovation and creativity are rarely demonstrated by employees who feel unappreciated and undervalued.

The latest research by the Gallup corporation has confirmed that only $15 \%$ of employees worldwide describe themselves as "fully engaged" at work (Clifton \& Harter, 2019). The failure of so many organizations lies in their disregard for the importance of treating employees as valued owners and partners, rather than as commodities (Block, 2013). Given how employees are currently treated, it is no surprise in today's work environment that that trust in leaders and organizations has declined (Harrington, 2017).

Although relationships with employees has long been described by eminent scholars as the key to long-term profitability (Pfeffer, 1998; Covey, 1992; Clifton \& Harter, 2019), many TMTs have chosen to adopt "command and control" philosophies that only serve to exacerbate the decline in employee commitment. Coupled with the influx of Generation $\mathrm{Z}$ workers who view their careers as far less important than free time (Masback, 2016), the task of creating successful organizations with highly committed employees is increasingly challenging. Given these varied human factors at play in today's global business world, it is no wonder that HRPs struggle in their quest to create successful organizational cultures in today's complex work context (Gomez-Mejia, Balkin, \& Cardy, 2015).

\section{Six Myths and Their Causes}

Struggling to generate profits, deal with competitor innovations and customer demands, and assess the impacts of the latest economic downturn, many TMTs struggle to allocate adequate time to HRM issues. Often organization leaders rely on "conventional wisdom" and dangerously incorrect paradigms in how they establish HRM policies (Pfeffer, 1998; Beer, 2009). Too busy to closely monitor HRPs, members of the TMT fall prey to six common HRM myths which color their thinking. Unfortunately, many HRPs lack adequate technical training and experience to recognize the fallacies in these same myths themselves. In this section we identify these myths, describe their negative consequences, and clarify how leaders and organizations can improve their HRM practices associated with each myth.

\subsection{MYTH 1: "HRM is Responsible for Hiring Employees"}

It is "best practice" for HRPs to involve department heads and subject matter experts in preparing a job analysis (Prien, Goodstein, Goodstein \& Gamble, 2009). The hiring decision is nonetheless a line decision that should be made by a department hiring authority (Picardi, 2019). HRPs can be a valuable source by helping the hiring authority to clarify job requirements, determining the most valid ways to measure the Bona Fide Occupational Qualifications of job candidates, and providing psychometric expertise in developing testing instruments. However, the decision of whether to hire a job applicant is not the HRPs but rests with the person responsible for that individual's supervision (Hunt, 2007).

HRM staff may take too great a role in the employee selection process for a variety of reasons. Sometimes HRPs with long tenure in their organizations acquire a great deal of political power. At other times, the technical skill and/or "blarney" of HRPs may intimidate department heads which are less assertive or confident. HRPs may influence the selection process by citing alleged legal requirements that they claim a department head must follow. TMTs who misunderstand the hiring process may also mandate that their HRM staff make the hiring decision for new personnel. Any of these causes for HRPs making hiring decisions distorts the staff role of the HRM function and can have a dysfunctional impact on an organization.

HRM departments can assist organizations in recruiting job applicants when new employee positions are created but HRPs are not the appropriate decision-makers in actually hiring employees (Lussier \& Hendon, 2018). Unfortunately, in many organizations, the screening process conducted by HRPs makes them de facto the determiners of individuals who are considered or hiring fby a department head. HRPs with strong personalities but a limited understanding of their roles may often dominate the hiring process - sometimes becoming "the personnel police" and virtually dictating a hiring decision (Caldwell \& Anderson, 2018).

\subsection{MYTH 2: "The Best Predictor of Future Behavior is Past Behavior"}

In a 2013 Psychology Today article, Dr. Karen Franklin examines the often-quoted maxim that past behavior is the best predictor of future performance. The idea is sometimes cited in personnel selection as the justification for hiring one candidate over another. Franklin (2013) suggested that reliance upon past performance was generated as a rule of thumb to save time and effort and has been widely accepted for decades. However, Franklin also explained that six specific conditions place limits on what she labeled a "gross oversimplification."

1) Frequently occurring habitual behaviors are more reliable than infrequently occurring behaviors.

2) Predictions tend to be most accurate over short time intervals. 
3) The situation for which behavior is predicted must be essentially identical to a past situation.

4) The behavior in question had not received corrective or negative feedback

5) The defining characteristics of the person must be essentially the same.

6) The person must be fairly consistent in her or his behaviors overall.

Franklin (2013) emphasized that the greatest problem with this generalization is that it unfairly classifies individuals. In addition, adopting this philosophy is in conflict with the premise that one of the great purposes of life for individuals is to grow and improve. As Derrick Bok (2020), former President of Harvard University has explained, the learning process affirms that every individual can learn, grow, change his or her behavior, and develop new knowledge and skills. "Lifelong learning" potential is an axiom of every culture (Baid, 2020), just as "creating a learning culture and continuous improvement have been acknowledged as fundamental requirements of every competitive organization (Senge, 2006). Similarly, the concept of repentance - or changing one's life to become a better person - is a foundation principle of virtually every religion in the world and is the spiritual counterpart of the secular principle, continuous improvement (Caldwell, Dixon, Atkins \& Dowdell, 2011).

HRPs sometimes discount the importance of "learning from mistakes" that affect candidates' careers and life experiences. The misconception that an individual's "error-free" professional background is the best predictor of success is evidenced by the failings of George McClellan and Ulysses S. Grant (Williams, 1991). McClellan was, on paper, far more suited to lead the northern forces than Ulysses S. Grant (Waugh, 2011). Ulysses S. Grant had barely been able to pass his classes at West Point, had an undistinguished military career in the War with Mexico, and was an unsuccessful businessman who failed miserably and ended up working as a clerk in his father's store. Despite his stellar West Point record, business success, and rank achieved in the Mexican War, McClellan failed as a military leader of the Northern forces in the Civil War. Grant, overcame his past failures and is acknowledged as the reason why the northern armies defeated their southern counterparts.

The reality is that HRPs need to understand the importance of getting "the right people on the bus" and getting those people into "the right seats" (Collins, 2001). Failing to conduct a job analysis that identifies the critical job skills necessary for success is a common HRP error. The premature assessment of candidates' abilities presumes that the past is the best predictor for the future when there are often important "flair factors" that need to be considered when evaluating job applicants (Caldwell, Beverage \& Converse, 2018). Disqualifying job candidates from hiring or promotional consideration because of career gaps or a work history in which the candidate had been employed by several employers is an all-too-common error made by HRPs. The history of great men and women confirms that people can learn, improve, change their lives, and make landmark contributions to society (O'Neill, 2020).

\subsection{MYTH 3: Employee Selection is Based Upon Identifying the Most Qualified Candidate}

Because many HRPs lack a clear understanding of the limits of testing or how to improve their testing and selection process, the assumption that testing enables their organizations to hire the best-qualified candidates among the many who apply is simply an inaccurate statement (Desjardins \& Bulut, 2018). Testing and selection competencies require a thorough understanding of statistical methods, as well as an awareness of the capabilities and limits of individual testing instruments (Rousseau \& Barends, 2011). The importance of validating qualifications required to successfully perform on the job is often overlooked - generating a "garbage in - garbage out" result, even if HRPs comprehend the complexities of measurement (Farr \& Tippins, 2017).

Candidate testing and evaluation is a difficult task that requires a broad set of skills that most HRPs neither understand nor possess (Price, 2016). That important lesson was learned by the Office of Strategic Services, the division of the American military system that oversaw the selection of individuals for undercover positions as international spies (Thornton \& Byham, 2013). Although the US military employed experts in psychology and test construction to evaluate potential candidates, many of the "best" applicants were killed before the experts recognized the importance of a complex set of behavioral skills that their testing had not previously measured (Smith, 2005).

HRPs have the very difficult task of identifying critical job skills and then designing or selecting testing instruments that accurately measure those qualifications. Testing guidelines define a test as any objective measure that is used to differentiate the job qualifications of applicants (American Psychological Association, 2019). When those tests are accurate predictors, they are considered valid measures of the Bona Fide Occupational Qualifications of the people being tested. Unfortunately, the psychometric evidence confirms that very few "valid tests" measure much more than $10 \%$ of the variance between job candidates (Furr, 2017). 
HRPs often choose to use "canned" testing materials purchased from vendors, despite the reality that those vendors have not properly validated those testing instruments. For example, the HRM staff of one US city purchased a promotional examination for its Police Department employees - but failed to carefully read the test validation study for that examination which indicated that the promotional exam had not been validated as an accurate predictor for testing ethnic minorities or women - and was, therefore, virtually unusable for the candidates being tested for promotion in that department.

HRPs who understand the complexities of the testing and selection process begin that process with a thorough and careful job analysis, involving subject matter experts who have a clear understanding of the essential tasks performed by new employees (Sackett \& Walmsley, 2012). Department heads and subject matter experts who participate in conducting the job analysis contribute to the quality of a selection process when they understand how each of the steps of that process is integrated to produce the best possible result (Wyse \& Babcock, 2018). TMT members who appreciate the importance of hiring skilled employees can become partners in improving the testing and selection process by supporting HRP efforts to ensure that the steps of that process meet the best practices of the HRM profession (Caldwell \& Anderson, 2018).

\subsection{MYTH 4: Hiring for the "Best Organizational Fit" is in an Organization's Best Interests}

Hiring people who possess the same biases, values, and perceptions may result in an organization where members agree without conflict - but that agreement may result in "groupthink" that stifles creative thinking and smothers team members' honest concerns about potential problems that are real but that they are nonetheless reluctant to bring up. This reluctance to speak openly and candidly about concerns can lead to disastrous decisions - like the tacit agreement of Ford employees who knew the dangers of the Pinto but were unwilling to confront that problem and its inevitable consequences (Gioia, 1992).

Department heads and selection committee members sometimes claim that their subjective perceptions and intuitive awareness of "person-organization fit" (Rivera, 2012) are the most valuable step in hiring a new employee (Westerman, 2004). The basis of this perception is that those individuals genuinely believe that they know what is best for the organization - when the outcome of their decision is more likely to simply replicate the hiring of "people like me" (Ross, 2014). "Fit" can become an unconscious justification for hiring people that personal preference - a self-justification are fraught with self-deception that is common but rarely fully understood in many people's lives (Arbinger, 2018).

Hiring practices that respect diversity -- including being open to hiring others with differing opinions and backgrounds - can enable organizations to examine issues from varying perspectives that improve the quality of decisions made (Allen, Dawson, Wheatley \& White, 2008). Diversity in hiring does not mean that organizations must have to deal with constant conflict. However, differences of perspective can also help to identify potential problems that would have been overlooked, as well as decision options that would have been unlikely to consider.

HRPs who understand the pitfalls of bias in hiring based upon fit understand that personal preferences and values in hiring undermine the ability to hire equitably and fairly. Those HRPs do their organizations a service by helping hiring authorities and selection committee members to recognize the pitfalls of personal bias in the selection process particularly at the interview stage (Alder \& Gilbert, 2006). Honoring both the requirements of the law and the spirit of the law are both important factors in hiring without preferential bias (dos Santos, Pais \& Cabo-Leitao, 2017).

To avoid hiring practices based upon personal bias, HRPs should clarify the downsides of that hiring practice with their TMTs and obtain their formal buy-in of hiring policies and practices that demonstrate a commitment to employee diversity and circumventing the dangers of conflict-avoidance thinking. By helping their TMTs to recognize the problems that can be caused by "hiring for fit" - as opposed to hiring based upon bona fide job qualifications - HRPs assist their organization to focus on selecting employees that are more likely to add value to their companies (Paauwe, 2004).

\subsection{MYTH 5: "Contracting Out HRM Functions Saves an Organization Money."}

Unfortunately, the "command and control" management philosophy continues to be de riguer in the minds of many organization leaders who tend to view the work force as a cost center to be minimized, rather than the source of a company's competitive advantage (Caldwell \& Anderson, 2018). Although the worldwide research about the importance of employee relations and the creation of high employee commitment has been affirmed by HRM.com, (2019), the thinking of many organization leaders is that employees are a fungible commodity that is easily exchanged and that employees are simply to be viewed as partners in a purely transactional relationship. 
The low regard in which HRM is held in many organizations has resulted in the mistaken belief that the HRM function is primarily limited to payroll and benefit administration, employee training, and the hiring of part-time and temporary employees (Cowling \& Mailer, 1998). Limited HRM expenses to those three functions broaden the responsibilities of managers and supervisors who, according to the latest worldwide research by the Gallup organization, are already deficient in employee relations skills and the source of much of the distrust of employees (Clifton \& Harter, 2019).

Although the seven roles of HRPs have been acknowledged as important by many experts in the HRM field (Gomez-Mejia, Balkin \& Cardy, 2015), minimizing those roles as HRP responsibilities that can be assumed by other line personnel demonstrates that TMTs simply fail to give much credence to the HRM role. However, the empirical research by Huselid and Jackson (1997) has found that when the HRM function is properly performed, organizations are more productive and save money.

Research about High-Performance Work Systems confirms that companies that align seven key HRM practices and strive to create high organizational trust are more profitable, more innovative, and more effective at providing excellent customer service than organizations that lack this alignment -- while also reducing employee turnover and increasing employee commitment (Pfeffer, 1998; Gittel, Seidner, \& Wimbush, 2010). The growing body of evidence about such systems, while limited in its influence in many organizations, is nonetheless an affirmation of the importance of the HRM roles when performed properly (Boxall \& Macky, 2009).

4.6 MYTH 6: HRPs Ensure That the Employee Hiring Process in Their Organizations Is Legal, Valid, and Technically Sound.

Although it is widely recognized that hiring top quality employees is a vital organizational function (Collins, 2001), TMTs rarely understand the legal, technical, and professional standards that go into the complex factors associated with employee hiring. The "employment-at-will" doctrine predominates in 49 of 50 states in the USA and the notion that employee hiring is legal as long as it is not challenged is the basic assumption of most organization leaders including a large percentage of HRPs (Olson, 1997; Villegas, Lloyd, \& Tritt, 2019).

The plain fact is that the legal system in most jurisdictions is heavily weighted in the employers' favor - even when the hiring process conducted by organizations of all types is "questionable" at best in its fairness, validity, and compliance with best practices of the HRM profession (Selmi, 1997). Although high profile cases involving large employers are the notable exception, in most cases job candidates have no legal recourse if they believe that they have been unfairly treated in a hiring process - even if they can make the case that their qualifications far exceed those of the person or persons ultimately hired.

The problem for HRPs is that they may recognize that they have little real ability to influence selection committees and department heads beyond advising them about fairness issues. The HRM staff function precludes HRPs from having decision-making authority in their relationships ith line managers - and many HRPs recognize that the arcane sophistication of testing and validity exceeds their knowledge level as well. The net result of many hiring processes is that they are never challenged although those processes may not produce the most qualified candidate from among the many who have applied for a job.

TMT members who have limited knowledge of employee selection and testing often find it difficult to assess the legality, much less the validity of their organizations' hiring practices. Typically, the most that a TMT member can do in assessing the legality of employee selection is to ask, "Is our hiring process free of adverse impact on protected classes?" Whether the process is legal is often measured in the minds of TMTs by the follow-up question, "Have any applicants filed suit against us?"

Technical issues about psychometric measurement, validity and reliability of testing instruments, and whether the weighting of important job factors and qualifications was properly assigned are issues that most TMT members do not have time to consider as they juggle what often seem to be a never-ending series of problems that constantly bombard them. Quietly, the issue "Is our hiring process generating the best candidate possible for each job?" rarely gets asked nor do most HRPs know the answer.

These six myths about HRM-related practices create major problems for today's organization leaders. The challenges faced by the modern organization and its TMTs are many and significant. Although the underlying issues associated with these myths may substantially affect the competitive advantage of their organizations, most TMTs - including those who are deeply committed to being both fair and effective in how their companies HRM programs are conducted - simply lack the information to accurately assess the effectiveness of the HRPs who work for them. 


\section{TMT Action Steps}

Because HRPs perform a staff role and their primary purpose is to assist the organization in accomplishing its strategic goals, the relationship between the HRPs and TMT is HRM's primary responsibility. Although HRPs have several stakeholders to whom they owe duties, the TMT is the entity to which HRM reports and is ultimately accountable. In directing the HRM team, the leaders of an organization can maximize the accountability of the HRPs by becoming subject matter experts regarding the HRM roles and responsibilities. The following are four essential action steps that the TMT should take to lead the HRM staff effectively.

1) Become informed about the contributions that world-class HRM services can contribute to an organization's strategic success. When company HRM systems fail to deliver services that are world-class, those companies are unable to perform at optimal levels. TMT members must understand the ramifications of failing to utilize their human capital resources. The clear evidence in today's knowledge-, wisdom-, and information-based economy is that committed and productive employees are the key to competitive success and long-term organization survival (Collins, 2001; Christensen \& Raynor, 2011; Covey, 2004).

2) Develop a profound understanding of the latest findings, critical terms, and range of functions that are required for HRPs to perform HRMs seven strategic roles. To appreciate the important contributions of an HRM system, the TMT must acquire a thorough and complete knowledge of the benefits available as HRM staff perform the seven strategic HRM roles. Failing to understand the purpose and benefits of those seven roles, the TMT will likely to recognize their vital nature to achieving organizational goals (Pfeffer, 1998).

3) Adequately fund HRM resources and staff to ensure that HRPs can implement the programs, policies, and priorities essential to facilitate the organization's strategic purposes. A comprehensive body of empirical evidence confirms that investing in the accomplishment of the HRM roles brings a positive return on investment for organizations - particularly when HRM programs, policies, and priorities are aligned with an organization's strategic purpose (Beer, 2009; Caldwell \& Anderson, 2018). Failing to provide the resources to carry out those seven HRM roles is false economy and is detrimental to a firm's economic success.

4) Establish metrics for measuring and monitoring HRM associated with the seven HRM roles and hold HRPs accountable to effectively carry out those roles. Time-targeted goals and clear process and performance objectives should be established to ensure that an organization's HRM staff have a clear understanding of the TMT's strategic plans for the organization. As part of this accountability process, a "champion" from the Top Management Team should work closely with the HRM Director to monitor the ongoing progress of HRPs in achieving established goals associated with the seven HRM roles.

These four action steps will enable the TMT to assist HRM staff to be optimally successful in serving the organization and its departments. These steps are important in aligning HRM programs and policies with a firm's strategic agenda and provide a process of both leadership and control that will enable HRP staff to perform their roles effectively (Ulrich et al., 2012).

\section{Conclusion}

As with other disciplines and professions, the HRM profession is complex and nuanced. The expertise demanded in filling the seven strategic roles of HRM is extensive and far more technically sophisticated than TMT members typically realize. Because so many of the individuals who work as HRPs are limited in their technical preparation for their jobs (Gomez-Mejia, Balkin \& Cardy, 2015), it is no wonder that the complexities of the HRM responsibilities are much more extensive than HRPs realize.

Even individuals with a Bachelors or Masters Degree with specializations in HRM are ill-prepared to understand and perform the broad-based responsibilities encompassed in the seven HRM strategic roles. Career professionals who have worked for many years in their profession are also guilty of not only believing one or more of the six myths described within this paper but in lacking the skill sets to perform all of the tasks required to excel at a world-class level. Yet, it is that high standard that is necessary for firms to distinguish themselves from their competitors (Collins, 2001; Christensen \& Raynor, 2011; Christensen, 2016).

There are no easy pathways for HRPs to follow to become highly competent in performing the many tasks that comprise the HRM function. The four suggestions offered in this paper represent a place to begin in raising the bar of HRM competence for HRP staff members. The ability of HRPs to contribute to the success of organizations depends, however, not only on their competences but on their skill in working with the TMTs who need to fully understand how HRM can benefit their organization. That understanding is not enough if those TMTs do not provide their HRPs with the resources necessary to accomplish the seven HRM roles. 
More than fifty years ago, H. L. Mencken correctly observed that for every complex problem there was an answer that was clear and simple - but inevitably wrong. So it is with the challenges inherent in raising the bar and improving the quality of HRM services provided in organizations. Simple solutions will not work - and passionate commitment and dedication to improving their knowledge and skills on the part of HRPs are necessary first steps. That progress, to be optimally successful, must also be aligned with the priorities of a TMT that understands how to utilize HRPs to create organizational cultures that mesh with organization strategies and goals - and that avoid the mistaken assumptions associated with the six myths identified herein.

A partial commitment of HRPs and their TMTs is far from sufficient. However, the pay-off measured by the improved selection of top talent and the development of those high-quality employees can help organizations to achieve their goals. Although, as Mencken suggested, the solutions to the problems facing organizations may be complex - and may require a broad array of HRM changes - the very nature of engaging, empowering, and motivating employees in collaborative efforts are much more likely to enable organizations to compete successfully in the $21^{\text {st }}$ century.

\section{References}

Arbinger Institute. (2018). Leadership and Self-Deception: Getting Out of the Box. San Francisco, CA: Berrett-Koehler Publishers.

Barney, J. B., \& Wright, P. M. (1998). On Becoming a Strategic Partner: The Role of Human Resources in Gaining a Competitive Advantage. Human Resource Management, 37(1), 31-46. https://doi.org/10.1002/(SICI)1099-050X(199821)37:1<31::AID-HRM4>3.0.CO;2-W

Beer, M. (2009). High Commitment High Performance: How to Build a Resilient Organization for Sustained Advantage. San Francisco, CA: Jossey-Bass.

Block, P. (2013). Stewardship: Choosing Service Over Self-Interest. New York: Pearson Publishing.

Caldwell, C., \& Anderson, V. (Eds). (2018). Strategic Human Resource Management. Hauppage, New York: NOVA Publishing.

Caldwell, C., Truong, D., Linh, P., \& Tuan, A. (2011). Strategic Human Resource Management as Ethical Stewardship. Journal of Business Ethics, 98(1), 171-182. https://doi.org/10.1007/s10551-010-0541-y

Christensen, C. M. (2016). The Innovator's Dilemma: When New Technologies Cause Great Firms to Fail. Boston, MA: Harvard Business Review Press.

Christensen, C. M., \& Raynor, M. E. (2013). The Innovator's Solution: Creating and Sustaining Successful Growth. Boston, MA: Harvard Business Review Press.

Clifton, J., \& Harter, J. (2019). It's the Manager. Omaha, NE: Gallup Press.

Collins, J., \& Hansen, M. T. (2011). Great by Choice. New York: Random House.

Collins, C. J., \& Clark, K.D., (2003). Strategic Human Resource Practices, Top Management Team Social Networks, and Firm Performance: The Role of Human Resource Practices in Creating Organizational Competitive Advantage. Academy of Management Journal, 46(6), 720-731. https://doi.org/10.2307/30040665

Covey, S. R. (1992). Principle-Centered Leadership. New York: Fireside Press.

Deming. W. E. (2000). Out of the Crisis. Cambridge, MA: MIT Press.

Gomez-Mejia, L. R., Balkin, D. B., \& Cardy, R. L. (2019). Managing Human Resources (9th ed.). London, UK: Pearson Publishing.

Hansen, M. T., (2019). Great at Work: The Hidden Habits of Top Performers. New York: Simon \& Schuster.

Harrington, M. (2017). Survey: People's Trust Has Declined in Business, Media, Government, and NGOs. Harvard Business Review, January 16, 2017. Retrieved September 23, 2020, from https://hbr.org/2017/01/survey-peoples-trust-has-declined-in-business-media-government-and-ngos

HR.Com. (2019). The State of Employee Engagement in 2019. Aurora, Canada: Glint.

Katz, L. F., \& Krueger, A. B. (2019). The Rise and Nature of Alternative Work Arrangements in the United States, 1995-2015. ILR Review, 72(2), 382-416. https://doi.org/10.1177/0019793918820008

Kotter, J. P. (2012). Leading Change, With a New Preface by the Author. Boston, MA: Harvard Business Review Press.

Kreitner, R., \& Kinicki, A. (2006). Organizational Behavior (10th ed.). Boston, MA: McGraw-Hill. 
Masback, G. (2016). The Voice of Gen Z: Understanding the Attitudes and Attributes of America's Next "Greatest Generation." Scotts Valley, CA: Create Space Independent Publishing.

Mintzberg, H., \& Caldwell, C., (2017). Leadership, 'Communityship,' and 'The Good Folk.' International Journal of Public Leadership, 13(1), 5-8. https://doi.org/10.1108/IJPL-12-2016-0053

Perez López, S., Peón, J. M. M., \& Ordás, C. J. V., (2005). Organizational Learning as a Determining Factor in Business Performance. The Learning Organization, 12(3), 227-245. https://doi.org/10.1108/09696470510592494

Pfeffer, J. (1998). The Human Equation: Building Profits by Putting People First. Boston, MA: Harvard Business Review Press.

Price, A. (2007). Human Resource Management in a Business Context (3rd ed.). Andover, Hampshire, UK: Cengage.

Schein, E. H., \& Schein, P. A. (2016). Organizational Culture and Leadership. San Francisco, CA: Jossey-Bass.

Ulrich, D., Younger, J., Brockbank, W., \& Ulrich, M., (2012). HR from the Outside In: Six Competencies for the Future of Human Resources. Boston, MA: McGraw-Hill.

\section{Copyrights}

Copyright for this article is retained by the author(s), with first publication rights granted to the journal.

This is an open-access article distributed under the terms and conditions of the Creative Commons Attribution license (http://creativecommons.org/licenses/by/4.0/). 